\title{
Intelligent Street Lighting
}

\author{
G. Vijay Krishna \\ M. Arch. (CPM), \\ Faculty of Architecture, Dr. M.G.R. Educational and research institute, Chennai, India.
}

\begin{abstract}
Street lighting is an expensive, most important and inevitable need in any city. With the current Conventional street lighting methodology, there is an abundant wastage of energy in areas with a low frequency of users and on the other hand the available lighting $d$ o not meet up the functional need of the users. By mere incorporation of lighting design standard with the available flexible-intelligent technologies and wireless internet connection, fast reactive, operationally dependable, and energy-conserving lighting systems becomes reality. This paper aims at the incorporation of various design standards and with the current flexible technology to enable street light system "an intelligent system" with optimal energy consumption.
\end{abstract}

Key words: intelligent street lighting, smart street lighting, street light design standards, street light controls.

\section{INTRODUCTION}

Street lighting is an expensive, most important and inevitable need in any city. Typically illumination accounts to $10-38 \%$ of cumulative energy bill worldwide (NYCGP 2009). Being a strategic element in social stability and economy, Street lighting is a critical concern of city development and maintenance authorities in developing countries.

India, a fast growing economy generates a total energy demand of 3,400 MW with the presence of 35 million street lights, has an expenditure of 2065 million \$ (13836CrINR). The energy demand for the street light supply is 21,900 million $\mathrm{kWh}$ annually as against the cumulative deficit of 38,138 million $\mathrm{kWh}$. Hence a nationwide programme of LED based street lighting retrofit is launched in the January, 2016 and aimed at replacing all the 35 million street lights with 770 million bulbs by March 2019. However the programme does not cover any intelligent lighting system and energy conservation, the objective of the system is to replace the current fixtures with that of the energy efficient LED fixtures.

Considering the current development in flexible technologies and wireless internet connectivity, a street lighting system with intelligence is practically possible.

This article deals about Intelligent Street Lighting System, that enables optimal lighting level based on the standards and conserves energy by reducing wastage enabling better monitor - control. Intelligently adaptable system depending on ambient light condition and user density, dynamic lighting levels or intensity controlled based on microprocessor and sensors are the prime topics dealt.

\section{ARCHITECTURE AND STANDARDS OF STREET LIGHT}

The standards of lighting system are categories based on the Current Street and road classifications. The classification of roads is shown in Table -1 , based on which the complete design and standards are arrived upon.

\begin{tabular}{|c|l|}
\hline Group & Details \\
\hline A1 & Rapid and dense traffic routes. Prime consideration is the speed and safety of the traffic. \\
\hline A2 & Mixed traffic routes such as arterial roads, main streets of the city, and thorough fares \\
\hline B1 & Secondary routes with moderate traffic. \\
\hline B2 & Secondary routes with light traffic \\
\hline C & Unclassified roads and residential roads \\
\hline
\end{tabular}




\begin{tabular}{|c|l|}
\hline D & Flyovers and bridges \\
\hline E & City / town centers \\
\hline F & Special requirement roads like airports and railways routes \\
\hline
\end{tabular}

Table 1. Road Classification (BIS, 1981)

The Street Light Poles and Mounting Height of Luminaries recommended by the Indian Standard, for the various categories of the road is shown in the table 2

Table - 2. Luminaries -Mounting height

\begin{tabular}{|c|c|}
\hline Road Group & Mounting Height \\
\hline A & $9-10$ mts. \\
\hline B & $7.5-9$ mts. \\
\hline Other & Less than 7.5 meters \\
\hline
\end{tabular}

Design parameters of the street light design is shown in figure -1
A: Angle of Tilt
Or: Outreach
$\mathrm{H}$ : Mounting Height
S: Spacing
O: Overhang
W: Width

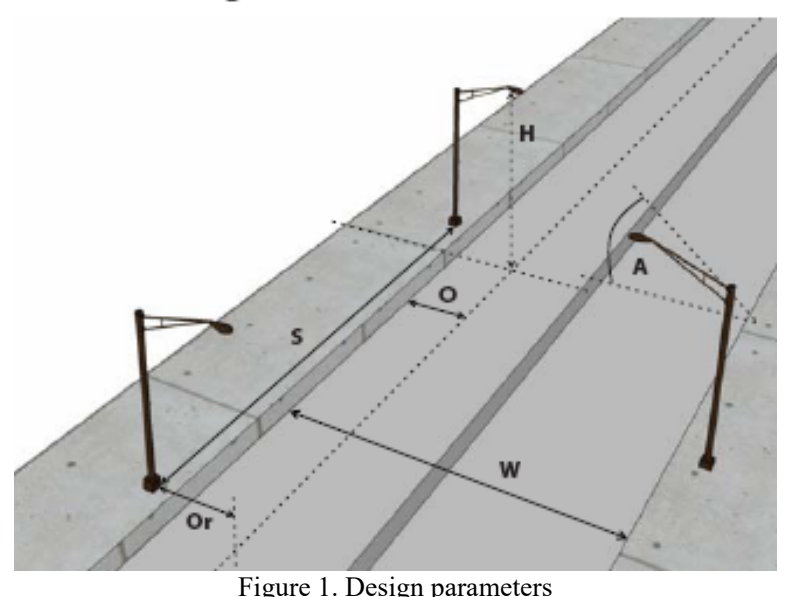

Spacing: Distance between the successive luminaries, measured along the center line of the road. The ratio between space and height is maintained more than 3 to ensure longitudinal uniformity.

Outreach: Horizontal distance between luminary mid to the luminary mounting pole center is termed as outreach.

Overhang: Distance between the mid of the luminary to the abutting edge of the road measure horizontally. The overhang is maintained at one-fourth the height of mounting for better visibility of curbs and footpath.

Siting of Luminaries: Siting of Luminaries are of four types.-

- Single side arrangement - Single side arrangement are followed when all luminaries are on same side of the road. The method is adopted when the road width is less or equal to the mounting height.

- Staggered arrangement - Staggered arrangement represents the luminaries placed in a zigzag format on either side of the road way. This method is followed when the width of the road is 1 to 1.5 times of the mounting height of the luminary. 
- Opposite mounting - when the road width is more than the mounting height by 1.5 times, Opposite mounting is adopted, where in the luminaries are located on either side of the road opposite to each another.

- Axial mounting - Axial mounting is followed in narrow roads, when the width of the road is not more the mounting height of the luminary. The axial mounting represents the luminaries located at the mid of the axis lane.

The illumination levels are defined by the group of the road where the system is being adopted. The illumination various categories of the road is shown in table 3

Table - 3 Mounting height of luminaries

\begin{tabular}{|c|l|c|c|}
\hline $\begin{array}{c}\text { Road } \\
\text { type }\end{array}$ & \multicolumn{1}{|c|}{ Characteristics of Road } & $\begin{array}{c}\text { Illumination on surface of } \\
\text { Road Surface (Lux) } \\
\text { Average value }\end{array}$ & $\begin{array}{c}\text { Ratio of Minimum and } \\
\text { Average Illumination }\end{array}$ \\
\hline A1 & $\begin{array}{l}\text { Rapid and dense traffic routes. Prime consideration } \\
\text { is the speed and safety of the traffic. }\end{array}$ & 30 & 0.4 \\
\hline A2 & $\begin{array}{l}\text { Mixed traffic routes such as arterial roads, main } \\
\text { streets of the city, and thorough fares }\end{array}$ & 15 & 0.4 \\
\hline B1 & Secondary routes with moderate traffic. & 8 & 0.3 \\
\hline B2 & Secondary routes with light traffic & 4 & 0.3 \\
\hline
\end{tabular}

The architecture and design consideration plays a vital role in the intelligent street light system as the optimal illumination without negative space is to be achieved, enabling the technology to integrate the further intelligence part.

\section{FLEXIBLE TECHNOLOGIES FOR INTELLIGENT STREET LIGHT}

The intelligence in street light can be achieved when the luminaries dynamically adjust its illumination level to meet the functional need of the streets. This parameter is met by the following methods .

- Control based out of day light sensors.

- $\quad \mathrm{IR}^{*}$ and PIR* based sensors controlled by micro process system

- Internet Communication based control system. (wireless technology)

\section{DAY LIGHT SENSORS BASED CONTROL:}

Day light based control system operates based on the ambient light level. The system is equipped with day light sensors. The trigger of the system would be controlled by timer system or would be altered by supply of energy. The day light sensors primarily operates based on the dimming of the lamps in presence of ambient light. Hence, the energy demand during the transition time is minimal to zero, there by energy conservation is enabled. The system operates automatically and no effort is wasted in operations. Day light sensor based system is considered as a first step towards the intelligent based street light system. The figure -2 shows the function of the day light sensor based system. 


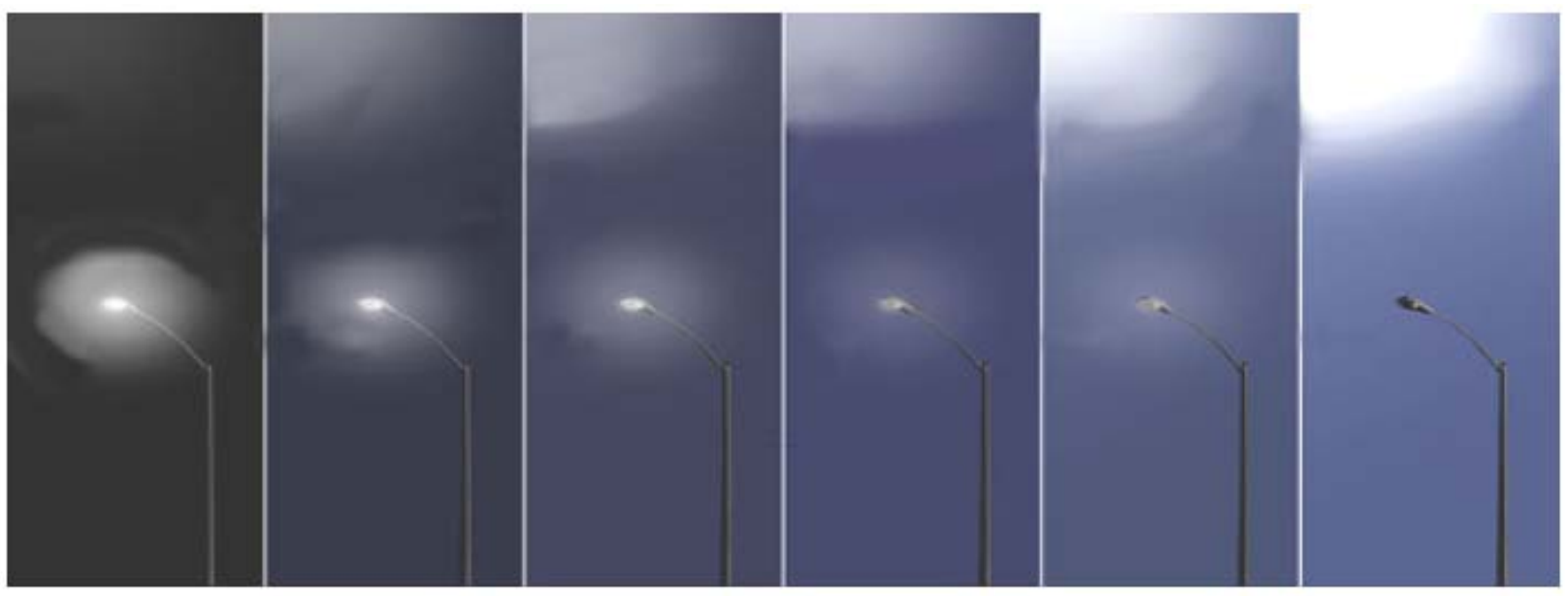

Figure 2. Day Light Sensor Control Functionality

The system can be adopted in streets where occupancy is high throughout the operational hours. Further, the system can be integrated with set of luminaries in a particular zone.

\section{IR* AND PIR* BASED SENSORS CONTROLLED BY MICRO PROCESSER SYSTEM}

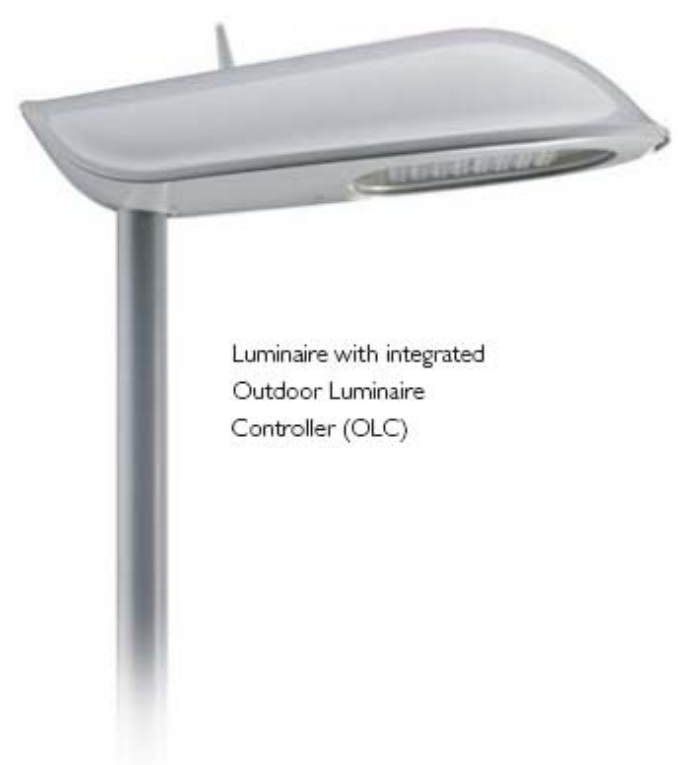

Figure 3. Schematics Of The Luminaries !

The system is equipped with IR and PIR based sensors, located at the terminal ends of the street to identify users movement and density. The sensors are strategically located at a distance to transfer information to its pier on the event detection. The bi-directional communication of sensors is enabled by wired communication. The micro processer analysis the system and modify the illumination level in the street. And on accomplishment of the event the illumination is reduced to original level, there by energy is conserved during every. The system can be implemented in a neighborhood where a single processor can control the luminaries in each loop separately or together, hence multiple streets can be controlled through one system. As the PIR sensors are located in both the ends the control is efficient. 
The system operates without any human effort there. The next level of advancement in intelligence is attained through the IR and PIR based system as this operates without consideration of the ambient lighting.

Further, the system can be incorporated with the Day light based system, where in the basic control of illumination during the transition is done through the Day light sensors and the remote hour operation is enabled through the PIR based controls. The integrated system further enables energy efficiency and a complete intelligence in the operation and control.

\section{INTERNET COMMUNICATION BASED CONTROL SYSTEM ICCS* (WIRELESS TECHNOLOGY):}

While, the day light sensor and IR/ PIR based system is effective in standalone or smaller street or neighborhood, the Internet communication based system is effective in controlling larger setup or on a city scale.

The luminary is connected with wireless integrated outdoor luminaries controller device which operates on the remote command through wireless ISP* network enabled through GSM* or CDMA* technologies. The figure - 3, shows the schematics of the luminaries.

The ICCS is a revolutionary, wireless tele-management system for monitoring, controlling, metering and diagnosing outdoor lighting. The system is based on two-way wireless communication using the latest in mesh network technology. The system enables individual light points to be switched on, dimmed, or off at any given time. They can also be set to any level, for instance, depending on traffic volume.

Additionally, use of the ICCS can increase light levels as needed for problem areas resulting in energy savings and reduced operating and maintenance costs while helping to improve the reliability of outdoor lighting.

With ICCS, the age and condition of each lamp can also be monitored, and any failures can be reported by exact location. Hence, an opportunity to reduce maintenance cost significantly by extended life of fixture and service scheduling is possible. Unlike the other system, this system can be used in monitoring the function and health of luminaries. The figure -4 , shows the schematics of the system architecture.

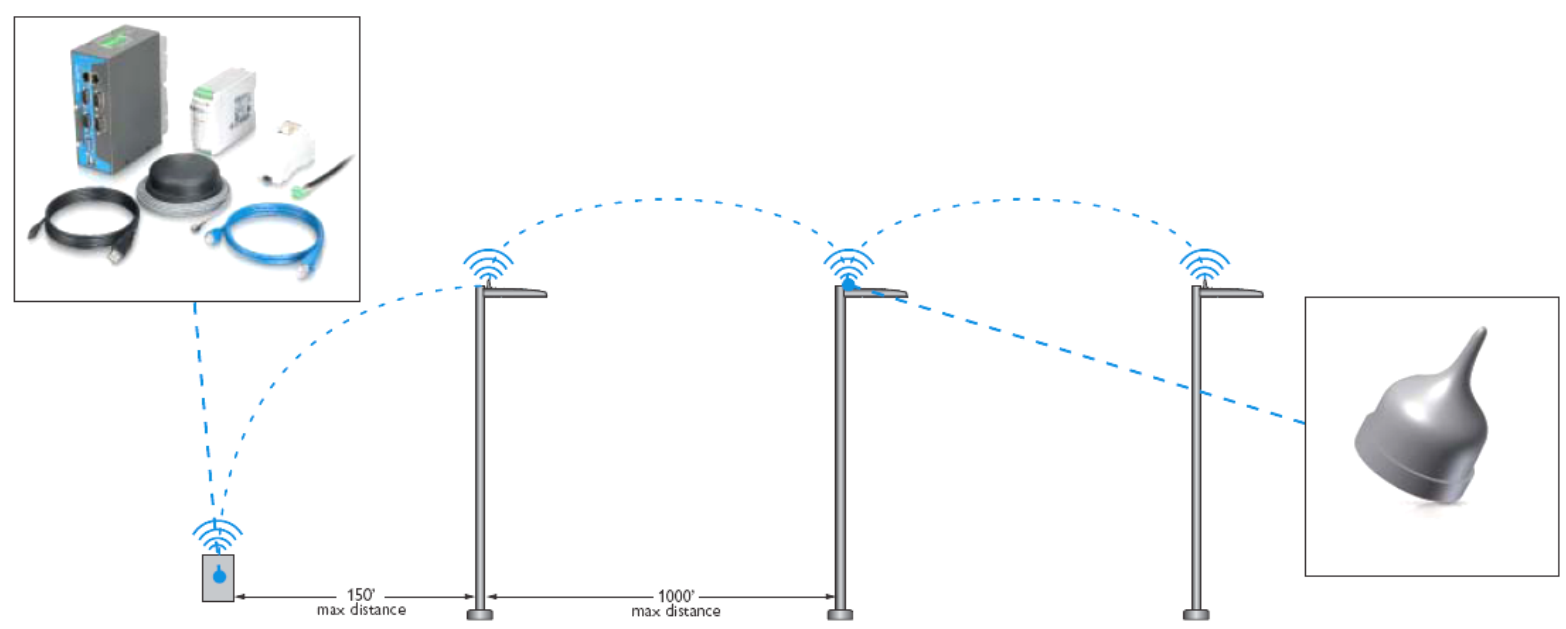

Figure 4. Schematics Of The system architecture.

\section{CONCLUSION}

The intelligence in street lighting system can be achieved through the above said various methods. However, the adaptation of the system can be based on the street typology, the functionality and the occupancy level. System with day light sensor control alone can be adopted in a main spine, where the average occupancy is noted throughout the time clock. On the other hand the ICCS based system is used in planning and controlling the city based setup or a highway project etc. 
In day today's context energy efficiency is achieved through the LED* fixtures, which reduces the energy demand by about $30 \%$, incorporation of the intelligent system further reduces the demand by $38 \%$ along with the other benefits in operations, monitor and control. The cumulative system would have a saving of $68 \%$ in the total street light energy demand.

Adaptation of renewable source of energy in the form of solar panels which can work in long with the intelligent technologies would further reduce the energy demand and creating a road map to carbon zero.

\section{ABBREVIATIONS *}

IR - Infra Red.

PIR - Passive Infra Red

ICCS - Internet Communication based Control System

LED - Light Emitting Diode

GSM - Global System for Mobile Communication

ISP - Internet Service Provider

MTS - Meters

CDMA - Code Division Multiple Access

\section{REFERENCES}

[1] Corporation of Chennai, 2003 - manual

[2] Lighting - Energy Efficient Street guidelines by Bureau of Indian Standards Version 2.0 - June, 2010

[3] The Energy and Resources Institute (TERI, New Delhi) manual 2016.

[4] Street lighting in India and need for energy- efficient solutions by Debu. C. Feb 2015.

[5] Leccese, F. , Remote-Control System of High Efficiency and Intelligent Street Lighting Using a ZigBee Network of Devices and Sensors, Power Delivery, IEEE Transactions on, p. 21 - 28 Volume: 28, Issue: 1, Jan. 2013

[6] Srivatsa, D.K.; Preethi, B.; Parinitha, R.; Sumana, G.; Kumar, A., Smart Street Lights, India Educators' Conference (TIIEC), 2013 Texas Instruments , p.103,106, 4-6 April 2013

[7] Wu Yue; Shi Changhong; Zhang Xianghong; Yang Wei, Design of new intelligent street light control system, Control and Automation (ICCA), 2010 8th IEEE International Conference on, p.1423,1427, 9-11 June 2010.

[8] Mendalka, M.; Gadaj, M.; Kulas, L.; Nyka, K., WSN for intelligent street lighting system, Information Technology (ICIT), $20102^{\text {nd }}$ International Conference on, vol., no., p.99,100, 28-30 June 2010. 